\title{
Is Energy Performance Capitalised in Office Building Appraisals?
}

\author{
Magnus Bonde and Han-Suck Song
}

\begin{abstract}
Purpose - Since 2009, all commercial buildings in Sweden should have undergone an energy performance rating in accordance with the European Union directive on the Energy Performance of Buildings. The main purpose of this rating is to illustrate a building's energy performance in an easy, straightforward, manner. In doing so, it becomes easier for the actors on the real estate market to assess the building's energy performance, which in the end should be reflected in the capital value of the property. The aim of this paper is to study the EU Energy Performance Certificates impact on office buildings' capital values.
\end{abstract}

Design/methodology/approach - In this paper an econometric approach is used to estimate the energy performance impact on buildings' capital values. A panel data set was constructed using economic data from IPD Nordic and Energy Performance Certificates from the Swedish National Board of Housing, Building and Planning.

Findings - This study shows that a building's energy performance has no impact on its capital value.

Research limitations/implications - There may be a selection bias in the sample as the study is dependent on data from IPD Nordic.

Originality/value - This is one of the first papers that study the EU Energy Performance Certificates impact on office buildings' capital values in Sweden.

Keywords: EPC, Energy Performance Certificate, capital value, hedonic price model, office buildings, Sweden

Article type: Research paper

Accepted manuscript, forthcoming in Property Management Vol 31 Issue 3 